\title{
Cyslabdan, a New Potentiator of Imipenem Activity against Methicillin-resistant Staphylococcus aureus, Produced by Streptomyces sp. K04-0144
}

\author{
I. Taxonomy, Fermentation, Isolation and Structural Elucidation \\ Atsushi Fukumoto, Yong-Pil Kim, Atsuko Matsumoto, Yoko Takahashi, Kazuro Shiomi, \\ Hiroshi Tomoda, Satoshi Ōmura
}

Received: October 5, 2007 / Accepted: November 1, 2007

(C) Japan Antibiotics Research Association

\begin{abstract}
Cyslabdan, a new potentiator of imipenem activity against methicillin-resistant Staphylococcus aureus, was isolated from the culture broth of Streptomyces sp. K04-0144 by Diaion HP-20 and ODS column chromatographies and preparative HPLC. The structure of cyslabdan was elucidated by spectroscopic analyses including NMR. The compound has a labdane-type diterpene skeleton connecting with an $\mathrm{N}$-acetylcysteine via thioether linkage.
\end{abstract}

Keywords cyslabdan, imipenem potentiator, methicillinresistant Staphylococcus aureus, MRSA, structural elucidation

\section{Introduction}

Methicillin-resistant Staphylococcus aureus (MRSA) is known as a major nosocomial pathogen which has also developed resistance to many other antibiotics [1]. Moreover, MRSA getting resistant to the last-resort antibiotic, vancomycin, has been reported [2, 3]. These facts suggest that MRSA would acquire more resistance to vancomycin in the near future. It is therefore increasingly

S. Ōmura (Corresponding author), A. Fukumoto, Y. Takahashi, K. Shiomi: Kitasato Institute for Life Sciences and Graduate School of Infection Control Sciences, Kitasato University, 5-9-1 Shirokane, Minato-ku, Tokyo 108-8641, Japan,

E-mail: omura-s@kitasato.or.jp important and necessary to find new antimicrobial agents and to devise new measures that are effective against MRSA infection.

Based on the new concept of "anti-infective drugs" developed by Ōmura [4], a screening system was established to search for microbial potentiators of imipenem activity against MRSA, and new stemphones were recently discovered from the culture broth of Aspergillus sp. FKI-2136 [5]. During our continuous screening program, an actinomycete strain K04-0144 was found to produce a strong potentiator of imipenem activity against MRSA. Activity-guided purification lead to the discovery of a novel compound designated cyslabdan (Fig. 1). From the structural elucidation, the fundamental

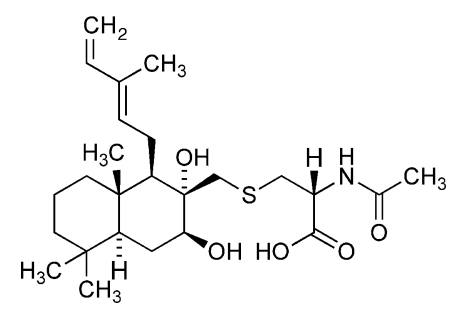

Fig. 1 Structure of cyslabdan.

H. Tomoda, Y.-P. Kim, A. Matsumoto, S. Ōmura: The Kitasato Institute, 5-9-1 Shirokane, Minato-ku, Tokyo 108-8642, Japan

H. Tomoda (Corresponding author): School of Pharmacy, Kitasato University, 5-9-1 Shirokane, Minato-ku, Tokyo 108-8641, Japan,

E-mail: tomodah@pharm.kitasato-u.ac.jp 
skeleton of cyslabdan is similar to that of totarol previously presented as a $\beta$-lactam potentiator [6]. As described in detail in the accompanying paper [7], cyslabdan showed almost no anti-MRSA activity by itself (MIC, $64 \mu \mathrm{g} / \mathrm{ml}$ ), but the compound $(10 \mu \mathrm{g} / \mathrm{ml}$, no activity against MRSA) enhanced the imipenem activity against MRSA over 1,000 folds, indicating that clinically resistant MRSA strains become clinically susceptible in the presence of cyslabdan.

In this study, the taxonomy of the producing strain, fermentation, isolation, and structural elucidation of cyslabdan are described.

\section{Materials and Methods}

\section{General Experimental Procedures}

Strain K04-0144 was isolated from a soil sample collected at Ishigakijima Island, Okinawa, Japan, and was used for production of cyslabdan. For determination of the amount of cyslabdan in culture broths, the samples dissolved in $\mathrm{MeOH}$ were analyzed by HP1100 system (HewlettPackard) under the following conditions: column, Symmetry $(2.1 \times 150 \mathrm{~mm}$, Waters Inc.); flow rate, $0.2 \mathrm{ml} /$ minute; mobile phase, a 20-minute linear gradient from 5.0\% $\mathrm{CH}_{3} \mathrm{CN} /$ $0.05 \% \mathrm{H}_{3} \mathrm{PO}_{4}$ to $100 \% \mathrm{CH}_{3} \mathrm{CN} / 0.05 \% \mathrm{H}_{3} \mathrm{PO}_{4}$; detection, $\mathrm{UV}$ at $210 \mathrm{~nm}$. The peak of cyslabdan was eluted with a retention time of 17.4 minutes.

UV spectra were recorded on a spectrophotometer (DU640, Beckman). IR spectra were recorded on a Fourier transform infrared spectrometer (FT-710, Horiba). Optical rotations were measured with a digital polarimeter (DIP370, JASCO). FAB-MS spectra and HR-FAB-MS spectra were recorded on a mass spectrometer (JMS-AX505HA, JEOL). The various NMR spectra were collected with a spectrometer (XL-400, Varian).

\section{Taxonomic Studies}

The International Streptomyces Project (ISP) media recommended by Shirling and Gottlieb [8] and media recommended by Waksman [9] were used to investigate the cultural and physiological characteristics. Cultures were routinely observed after the incubation for two weeks at $27^{\circ} \mathrm{C}$. Color names and hue numbers were determined according to the Color Harmony Manual [10]. The utilization of carbon sources was tested by growth on Pridham and Gottlieb's medium containing $1.0 \%$ carbon at $27^{\circ} \mathrm{C}$ [11]. The morphological properties were observed with a scanning electron microscope (model JSM-5600, JEOL). The type of diaminopimelic acid (DAP) isomers was determined by the method of Becker et al. [12]. Menaquinones were extracted and purified by the method of Collins et al. [13], then were analyzed by HPLC (Gulliver System, JASCO) equipped with a Capcell Pak C18 column $(4.6 \times 250 \mathrm{~mm}$, Shiseido) [15].

\section{Absolute Sterochemistry of Amino Acid Residue}

To detemine the configuration of $\mathrm{N}$-acetylcysteine, cyslabdan was cleaved to labdane skeleton and $\mathrm{N}$ acetylalanine, by hydrogenation with Raney nickel as a catalyst [16 19]. The absolute configuration of $N$ acetylalanine was determined by direct comparison of the retention times of the authentic $N$-acetyl-L-alanine and $\mathrm{N}$-acetyl-D-alanine by HPLC (column, Sumichiral OA-5000 $(4.6 \times 250 \mathrm{~mm})$; solvent, $2.0 \mathrm{mM} \mathrm{CuSO}{ }_{4}$ in $5.0 \% \mathrm{CH}_{3} \mathrm{CN}$; flow rate, $1.0 \mathrm{ml} /$ minute; detection, $254 \mathrm{~nm}$ ).

\section{Results}

\section{Taxonomy of the Producing Strain}

The vegetative mycelia grew abundantly on yeast extract malt extract agar, inorganic salts - starch agar and others, and did not show fragmentation into coccoid forms or bacillary elements. The color of vegetative mycelia showed pale yellow. The aerial mycelia grew abundantly on yeast extract - malt extract and glycerol - asparagine agar and the aerial mass color showed white to gray. From observation of the scanning electron micrograph of the strain (Fig. 2), the spore chains were spiral and each had more than 20 spores per chain. The spores were cylindrical in shape, $1.0 \times 1.0 \sim 1.2 \mu \mathrm{m}$ in size and had a smooth surface. Whirls, sclerotic granules, sporangia and flagellate spores were not observed. Growth temperature range was $12^{\circ} \mathrm{C}$ to $42^{\circ} \mathrm{C}$. DGlucose, D-mannitol, melibiose and L-rhamnose were used well, and L-arabinose, D-fructose, myo-inositol, raffinose, sucrose and D-xylose were used slightly as sole carbon. Melanoid pigment and other soluble pigments were not produced. Hydrolysis of starch was positive, and

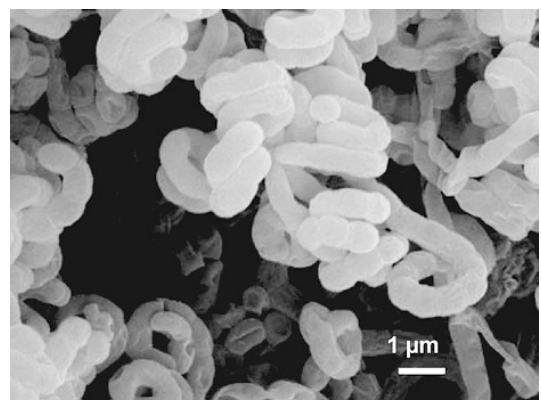

Fig. 2 Scanning electron micrograph of Streptomyces sp. K04-0144.

Bar represents $1 \mu \mathrm{m}$ 
coagulation and peptonization of milk were positive.

The isomer of DAP in whole-cell hydrolysates of strain K04-0144 was determined to be LL-form. Major menaquinones were MK-9 $\left(\mathrm{H}_{6}\right)$ and MK-9 $\left(\mathrm{H}_{8}\right)$.

Based on the taxonomic properties described above, strain K04-0144 (NITE BP-107) is considered to belong to the genus Streptomyces [14].

\section{Fermentation}

A slant culture of the strain K04-0144 grown on the slant medium (starch $1.0 \%, \mathrm{~N}$-Z-amine $0.3 \%$, yeast extract $0.02 \%$, meat extract $0.1 \%, \mathrm{CaCO}_{3} 0.3 \%$, agar $1.2 \%$, pH 7.0) was used to inoculate five 500-ml Erlenmeyer flasks each containing $100 \mathrm{ml}$ of the seed medium (starch $2.4 \%$, glucose $0.1 \%$, peptone $0.3 \%$, yeast extract $0.5 \%, \mathrm{CaCO}_{3}$ $0.4 \%, \mathrm{pH} 6.0)$. The flasks were shaken on a rotary shaker at $27^{\circ} \mathrm{C}$ for 3 days. The seed culture $(500 \mathrm{ml})$ was transferred into a 90-liter jar fermenter containing 50 liters of the production medium (glucose $0.5 \%$, corn steep powder $0.5 \%$, oatmeal $1.0 \%$, Pharmamedia $1.0 \%, \mathrm{~K}_{2} \mathrm{HPO}_{4} 0.5 \%$, $\mathrm{MgSO}_{4} \cdot 7 \mathrm{H}_{2} \mathrm{O} \quad 0.5 \%$, trace salts solution (containing $\mathrm{FeSO}_{4} \cdot 7 \mathrm{H}_{2} \mathrm{O} \quad 0.1 \%, \mathrm{MnCl}_{2} \cdot 4 \mathrm{H}_{2} \mathrm{O} \quad 0.1 \%, \mathrm{ZnSO}_{4} \cdot 7 \mathrm{H}_{2} \mathrm{O}$ $0.1 \% \mathrm{CuSO}_{4} \cdot 5 \mathrm{H}_{2} \mathrm{O} 0.1 \%$, and $\mathrm{CoCl}_{2} \cdot 6 \mathrm{H}_{2} \mathrm{O} 0.1 \%$ ) $0.1 \%$, $\mathrm{pH}$ 7.0). The fermentation was carried out at $27^{\circ} \mathrm{C}$ for 6 days with an aeration of 5.0 liters/minute and an agitation of $200 \mathrm{rpm}$. A typical time course of the fermentation is shown in Fig. 3. The production of cyslabdan was observed at day 1 after inoculation, and reached a maximum $(2.3 \mu \mathrm{g} / \mathrm{ml})$ at day 5 .

\section{Isolation}

The 6-day old culture broth (50 liters) was centrifuged to separate the mycelium and supernatant. The supernatant

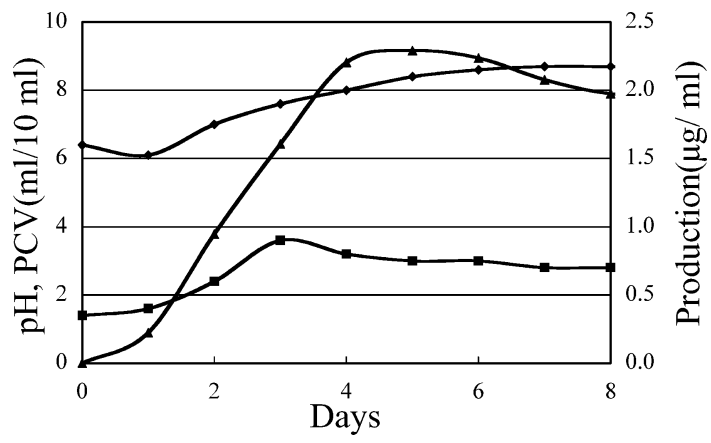

Fig. 3 A time course of cyslabdan production by Streptomyces sp. K04-0144.

At the indicated times, whole culture broth $(10 \mathrm{ml})$ was removed from the flask, and centrifuged at 3,000 rpm. The $\mathrm{pH}$ of the supernatant and packed cell volume (PCV, $\mathrm{ml}$ ) were measured. The amount of cyslabdan was determined by HPLC as described in Materials and Methods. $\bullet$; $\mathrm{pH}, \mathbf{\square}$; PCV, $\mathbf{\Delta}$; production. was applied on a Diaion HP-20 column $(100 \times 200 \mathrm{~mm}$, Mitsubishi Chemical. Co.). After washing with $\mathrm{H}_{2} \mathrm{O}$, active principles were eluted with $\mathrm{MeOH}$ and concentrated in vacuo to dryness to yield brown oily materials ( $32 \mathrm{~g}$ ). The materials were dissolved in $\mathrm{H}_{2} \mathrm{O}$, and undesired materials were removed by extraction with EtOAc. The $\mathrm{H}_{2} \mathrm{O}$ layer was concentrated to yield brown materials $(27 \mathrm{~g})$. A half of the materials were dissolved in a small volume of $\mathrm{H}_{2} \mathrm{O}$ and applied on an ODS column $(50 \times 280 \mathrm{~mm})$. Materials were eluted stepwise with 40, 60, 80 and 100\% MeOH (4.0 liters each). The $80 \% \mathrm{MeOH}$ fraction showing the activity was concentrated to give brown materials (134 mg). The materials were finally purified by HPLC (column, PEGASIL ODS (Senshu Scientific. Co.) $20 \times 250 \mathrm{~mm}$; mobile phase, $60 \% \mathrm{CH}_{3} \mathrm{CN}$ containing $0.05 \% \mathrm{H}_{3} \mathrm{PO}_{4}$; flow rate, $8.0 \mathrm{ml} /$ minute; detection, $\mathrm{UV}$ at $210 \mathrm{~nm}$ ). Under these conditions, cyslabdan was eluted as a peak with a retention time of 32 minutes. The fraction was applied on a Diaion HP-20 column to remove $\mathrm{H}_{3} \mathrm{PO}_{4}$. After washing with $\mathrm{H}_{2} \mathrm{O}$, cyslabdan was eluted with $\mathrm{MeOH}$ and concentrated to yield a white powder $(17 \mathrm{mg})$.

\section{Structural Elucidation}

Physico-chemical properties of cyslabdan are summarized in Table 1. The IR absorption at $3427 \mathrm{~cm}^{-1}$ suggested the presence of a hydroxy residue in the structure. The molecular formula was determined as $\mathrm{C}_{25} \mathrm{H}_{41} \mathrm{NO}_{5} \mathrm{~S}$ on the basis of HRFAB-MS measurement. The ${ }^{13} \mathrm{C}-\mathrm{NMR}$ spectrum showed 25 resolved peaks, which are classified into five methyl carbons, eight methylene carbons, four $s p^{3}$

Table 1 Physico-chemical properties of cyslabdan

\begin{tabular}{|c|c|}
\hline Appearance & : White powder \\
\hline Melting point & $: 138^{\circ} \mathrm{C}$ \\
\hline Molecular formula & $: \mathrm{C}_{25} \mathrm{H}_{41} \mathrm{NO}_{5} \mathrm{~S}$ \\
\hline Molecular weight & $: 467$ \\
\hline Pos. FAB-MS (m/z) & $: 512[\mathrm{M}-\mathrm{H}+2 \mathrm{Na}]^{+}$ \\
\hline \multicolumn{2}{|l|}{ HR Pos. FAB-MS (m/z) } \\
\hline Obsd. & : 512.2416 \\
\hline Calcd. & $: 512.2423\left(\mathrm{C}_{25} \mathrm{H}_{40} \mathrm{NO}_{5} \mathrm{SNa}_{2}\right)$ \\
\hline$[\alpha]_{D}^{25}$ & $:+26.8\left(c 0.1, \mathrm{CH}_{3} \mathrm{OH}\right)$ \\
\hline UV $\lambda_{\max }^{\mathrm{CH}_{3} \mathrm{OH}} \mathrm{nm}(\log \varepsilon)$ & : $232(4.19)$ \\
\hline $\mathrm{IR} v_{\max }^{\mathrm{KBr}} \mathrm{Cm}^{-1}$ & $\begin{aligned}: & 3427,2927,2864,1641,1604 \\
& 1398,1124\end{aligned}$ \\
\hline \multicolumn{2}{|l|}{ Solubility } \\
\hline Soluble & $: \mathrm{H}_{2} \mathrm{O}, \mathrm{CH}_{3} \mathrm{CN}, \mathrm{CH}_{3} \mathrm{OH}$ \\
\hline Insoluble & : EtOAc, $\mathrm{CHCl}_{3}, n$-Hexane \\
\hline \multicolumn{2}{|l|}{ Color reaction } \\
\hline Positive & : Molybdatophosphoric acid \\
\hline Negative & $: \mathrm{H}_{2} \mathrm{SO}_{4}$, ninhydrin reagent \\
\hline
\end{tabular}


Table $2{ }^{1} \mathrm{H}$ - and ${ }^{13} \mathrm{C}$-NMR data of cyslabdan

\begin{tabular}{|c|c|c|}
\hline No. & $\delta_{\mathrm{C}}(\mathrm{M})$ & $\delta_{\mathrm{H}}$ \\
\hline 1 & $41.1(\mathrm{t})$ & $0.84(2 \mathrm{H}, \mathrm{m})$ \\
\hline \multirow[t]{2}{*}{2} & $19.3(t)$ & $1.35(1 \mathrm{H}, \mathrm{m})$ \\
\hline & & $1.63(1 \mathrm{H}, \mathrm{m})$ \\
\hline \multirow[t]{2}{*}{3} & $43.0(\mathrm{t})$ & $1.14(1 \mathrm{H}, \mathrm{m})$ \\
\hline & & $1.63(1 \mathrm{H}, \mathrm{m})$ \\
\hline 4 & 34.1 (s) & \\
\hline 5 & 53.7 (d) & $0.91(1 \mathrm{H}, \mathrm{m})$ \\
\hline 6 & $27.8(t)$ & $1.63(2 \mathrm{H}, \mathrm{m})$ \\
\hline 7 & $72.3(d)$ & $3.82(1 \mathrm{H}, \mathrm{dd}, J=4.5,11.0)$ \\
\hline 8 & 78.8 (s) & \\
\hline 9 & $55.2(d)$ & $1.35(1 \mathrm{H}, \mathrm{m})$ \\
\hline 10 & $39.8(\mathrm{~s})$ & \\
\hline \multirow[t]{2}{*}{11} & $24.4(t)$ & $2.13(1 \mathrm{H}, \mathrm{m})$ \\
\hline & & $2.42(1 \mathrm{H}, \mathrm{dt}, J=6.5,17.0)$ \\
\hline 12 & $137.6(d)$ & $5.55(1 \mathrm{H}, \mathrm{t}, J=6.5)$ \\
\hline 13 & 133.2 (s) & \\
\hline 14 & $143.1(d)$ & $6.35(1 \mathrm{H}, \mathrm{dd}, J=10.0,18.0)$ \\
\hline \multirow[t]{2}{*}{15} & $110.1(t)$ & $4.86(1 \mathrm{H}, \mathrm{d}, J=10.0)$ \\
\hline & & $5.03(1 \mathrm{H}, \mathrm{dd} J=18.0)$ \\
\hline 16 & $12.0(q)$ & $1.75(3 \mathrm{H}, \mathrm{bs})$ \\
\hline \multirow[t]{2}{*}{17} & $39.2(\mathrm{t})$ & $2.63(1 \mathrm{H}, \mathrm{d}, J=12.5)$ \\
\hline & & $2.77(1 \mathrm{H}, \mathrm{d}, J=12.5)$ \\
\hline 18 & $34.0(q)$ & $0.91(3 \mathrm{H}, \mathrm{s})$ \\
\hline 19 & $22.3(q)$ & $0.84(3 \mathrm{H}, \mathrm{s})$ \\
\hline 20 & $16.0(q)$ & $1.00(3 \mathrm{H}, \mathrm{s})$ \\
\hline $1^{\prime}$ & 177.4 (s) & \\
\hline $2^{\prime}$ & $55.8(d)$ & $4.41(1 \mathrm{H}, \mathrm{dd}, J=4.5,8.0)$ \\
\hline \multirow[t]{2}{*}{$3^{\prime}$} & $37.7(\mathrm{t})$ & $2.82(1 \mathrm{H}, \mathrm{dd}, J=8.0,13.0)$ \\
\hline & & $3.02(1 \mathrm{H}, \mathrm{dd}, J=4.5,13.0)$ \\
\hline $4^{\prime}$ & 172.5 (s) & \\
\hline $5^{\prime}$ & $22.8(q)$ & $1.98(3 \mathrm{H}, \mathrm{s})$ \\
\hline
\end{tabular}

${ }^{1} \mathrm{H}-\mathrm{NMR}$ : $400 \mathrm{MHz}$ in $\mathrm{CD}_{3} \mathrm{OD}$ (ref. $3.31 \mathrm{ppm}, J$ value in $\mathrm{Hz}$ ).

${ }^{13} \mathrm{C}-\mathrm{NMR}$ : $100 \mathrm{MHz}$ in $\mathrm{CD}_{3} \mathrm{OD}$ (ref. $49.0 \mathrm{ppm}$ ), M: multiplicity.

methine carbons, two $s p^{2}$ methine carbons, three $s p^{3}$ quaternary carbons and three $s p^{2}$ quaternary carbons by analysis of the DEPT spectra. The ${ }^{1} \mathrm{H}-\mathrm{NMR}$ spectrum (in $\mathrm{CD}_{3} \mathrm{OD}$ ) displayed 37 proton signals. The connectivity of proton and carbon atoms (Table 2) was established by the HMQC spectrum. Analayses of the ${ }^{1} \mathrm{H}-{ }^{1} \mathrm{H}$ COSY revealed the presence of the five partial structures I to $\mathrm{V}$ as shown in Fig. 4. Furthermore, ${ }^{13} \mathrm{C}-{ }^{1} \mathrm{H}$ long-range couplings of ${ }^{2} J$ and ${ }^{3} \mathrm{~J}$ observed in the ${ }^{13} \mathrm{C}-{ }^{1} \mathrm{H}$ HMBC spectrum (Fig. 5) gave the following linkages: 1$)$ The cross peaks from $\mathrm{H}_{3}-19$ $(\delta 0.84)$ to $\mathrm{C}-3(\delta 43.0), \mathrm{C}-4(\delta 34.1)$ and $\mathrm{C}-5(\delta 53.7)$ and from $\mathrm{H}_{3}-18(\delta 0.91)$ to $\mathrm{C}-3, \mathrm{C}-4$ and $\mathrm{C}-5$ showed the connection between the partial structures I and II. 2) The cross peaks from $\mathrm{H}-7$ ( $\delta 3.82)$ to $\mathrm{C}-8(\delta$ 78.8), C-9 $(\delta 55.2)$
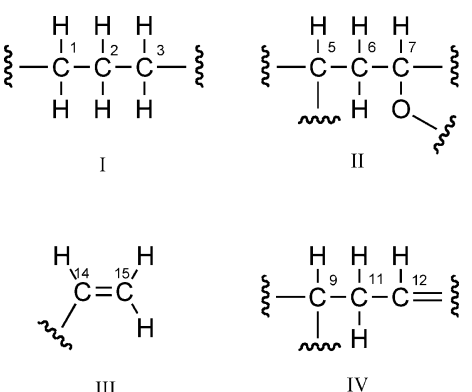

IV

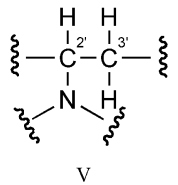

Fig. 4 Partial structures of cyslabdan.

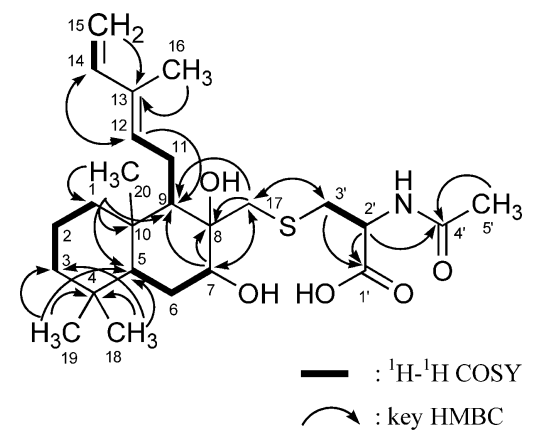

Fig. $5{ }^{1} \mathrm{H}-{ }^{1} \mathrm{H}$ COSY and ${ }^{13} \mathrm{C}-{ }^{1} \mathrm{H}$ HMBC experiments of cyslabdan.

and $\mathrm{C}-17(\delta 39.2)$, from $\mathrm{H}_{2}-17(\delta 2.63,2.77)$ to $\mathrm{C}-7$ $(\delta 72.3), \mathrm{C}-8$ and $\mathrm{C}-9$, and from $\mathrm{H}_{3}-20(\delta 1.00)$ to $\mathrm{C}-1$ $(\delta$ 41.1), C-5, C-9 and C-10 ( $\delta$ 39.8), showed the connection among the partial structures I, II and III, indicating the presence of a labdane skeleton. 3$)$ The cross peaks from $\mathrm{H}_{2}-15(\delta 4.86,5.03)$ to $\mathrm{C}-13(\delta$ 133.2), from $\mathrm{H}_{3}-16(\delta 1.75)$ to $\mathrm{C}-13$ and from $\mathrm{H}-14(\delta 6.35)$ to $\mathrm{C}-12$ $(\delta$ 137.6) showed the connection between the partial structures III and IV. 4) The cross peaks from $\mathrm{H}_{2}-3^{\prime}$ $(\delta 2.82,3.02)$ to $\mathrm{C}-17$ and chemical shifts of $\mathrm{C}-3^{\prime}$ suggested connection between the partial structure $\mathrm{V}$ and the labdanic skeleton via thioether linkage. 5) The cross peaks from $\mathrm{H}_{2}-^{\prime}{ }^{\prime}$ to $\mathrm{C}-1^{\prime}(\delta 177.4)$, from $\mathrm{H}-2^{\prime}(\delta 4.41)$ to $\mathrm{C}-1^{\prime}$ and $\mathrm{C}-4^{\prime}\left(\delta\right.$ 172.5) and from $\mathrm{H}_{3}-5^{\prime}\left(\delta\right.$ 1.98) to $\mathrm{C}-4^{\prime}$ and chemical shifts of $\mathrm{C}-1^{\prime}$ and $\mathrm{C}-4^{\prime}$ suggested the presence of $\mathrm{N}$-acetylcysteine. Taken together, the structure of cyslabdan was elucidated as shown in Fig. 5. 


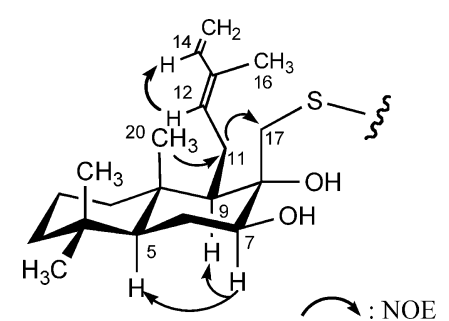

Fig. 6 Key NOE correlations of cyslabdan.

\section{Configuration}

NOE experiments suggested the relative configuration of the diterpene part (Fig. 6). Irradiation at H-12 ( $\delta$ 5.55) produced NOE enhancement of the signals of H-14 ( $\delta 6.35)$, but not of the signal of $\mathrm{H}_{3}-16(\delta 1.75)$, suggesting $12 E$-configuration. The trans-decalin configuration was indicated by the absence of NOE enhancement at H-5 ( $\delta$ 0.91) when $\mathrm{H}_{3}-20(\delta$ 1.00) was irradiated. Irradiation at H-7 ( $\delta$ 3.82) (axial proton geminal to the hydroxyl substituent) produced NOE enhancements of the signals of H-5 ( $\delta$ 0.91) and H-9 ( $\delta$ 1.35), but not of the signal of $\mathrm{H}_{2}-11(\delta 2.13,2.42)$ and $\mathrm{H}_{2}-17(\delta 2.63,2.77)$. Therefore, H-5, H-7 and H-9 were suggested to be on the same side of decalin plane. Furthermore, NOEs betweeen $\mathrm{H}_{3}-20$ $(\delta 1.00) / \mathrm{H}_{2}-11(\delta 2.13,2.42)$ and $\mathrm{H}_{2}-11(\delta 2.13,2.42) /$ $\mathrm{H}_{2}-17(\delta 2.63,2.77)$ indicated the configuration of $\mathrm{C}-8$ and $\mathrm{C}-9$. Thus, the relative configuration of the labdane skeleton was shown to be (12E)-labda-12,14-dien-7 $\beta, 8 \alpha$ diol.

To elucidate the configuration of $N$-acetylcysteine, cyslabdan was degraded as described in Materials and Methods. Under the HPLC conditions, the retention times of the authentic $N$-acetyl-L-alanine and $N$-acetyl-D-alanine were 9.25 and 10.57 minutes, respectively. Since the obtained $N$-acetylalanine was eluted with the retention time of 9.25 minutes, it was identified as $N$-acetyl-L-alanine. Therefore, the absolute configuration of $N$-acetylcysteine part of cyslabdan was elucidated as L-form.

\section{Discussion}

In this study, cyslabdan was isolated from the streptomycete metabolites, and the structure was elucidated to be a labdane-type diterpene skeleton connecting with an $N$-acetylcysteine via thioether likage. Furthermore the relative configuration of the labdane part and the absolute configuration of the $N$-acetylcysteine part were demonstrated. By comparison with the structure of plant labdane diterpenoids [20 23], the total absolute configuration of cyslabdan was suggested as shown in Fig. 1.

However, there are two different parts of the stereochemistry between actinomycete cyslabdan and plant labdanes; 1) regarding the double bond at C-12, cyslabdan has $12 E$-configuration, while some plant labadanes have 12Z-configuration [20], and 2) regarding the hydroxy moiety at C-7, cyslabdan and nidorellol from plants Nidorella spp. show $7 S$ configuration, while the labdane isolated from liverwort Porella perrottetiana shows $7 R$ $[22,23]$. Labdane diterpenoids had been isolated only from plant metabolites. Therefore, cyslabdane is the first actinomycete metabolite having a labdane-type diterpene structure.

Moreover, cyslabdan has a thioether-linked $N$-acetylL-cysteine moiety. Several compounds having an $N$ acetylcysteine of actinomycete orgin have been reported, and their configurations are all L-form as well as cyslabdan $[24,25]$.

Cyslabdan was found to strongly enhance the $\beta$-lactam imipenem activity against MRSA. The potentiation indicates that clinically resistant MRSA strains become clinically susceptible in the presence of cyslabdan. The biological activity of cyslabdan will be described in detail in the accompanying study.

Acknowledgments This study was supported in part by the grant of the 21st Century COE Program, Ministry of Education, Culture, Sports, Science and Technology, Japan. We thank Dr. H. Hanaki for providing us with the MRSA clinical strain. We express our thanks to Ms. N. Sato for NMR experiments, Ms. T. Sakabe and Ms. A. Nakagawa for mass spectra.

\section{References}

1. Tomasz A. Multiple-antibiotic resistant pathogenic bacteria. New England J Med 330: 1247-1251 (1994)

2. Hiramatsu K, Hanaki H, Ino T, Yabuta K, Oguri T, Tenover FC. Methicillin-resistant Staphylococcus aureus clinical strain with reduced vancomycin susceptibility. J Antimicrob Chemother 40: 135-136 (1997)

3. Centers for Disease Control and Prevention. Staphylococcus aureus with reduced susceptibility to vancomycin-United States, 1997. MMWR Morb Mortal Wkly Rep 46: 765-766 (1997)

4. Ōmura S. Antiinfective drugs into the 21 st century. Nippon Saikingaku Zasshi 54: 795-813 (1999) (in Japanese)

5. Koyama N, Nagahiro T, Yamaguchi Y, Masuma R, Tomoda $\mathrm{H}$, Ōmura S. Stemphones, novel potentiators of imipenem activity against methicillin-resistant Staphylococcus aureus, produced by Aspergillus sp. FKI-2136. J Antibiot 58: 695-703 (2005) 
6. Nicolson K, Evans G, O'Toole PW. Potentiation of methicillin activity against methicillin-resistant Staphylococcus aureus by diterpenes. FEMS Microbiol Lett 179: 233-239 (1999)

7. Fukumoto A, Kim YP, Hanaki H, Shiomi K, Tomoda H, Ōmura S. Cyslabdan, a new potentiator of imipenem activity against methicillin-resistant Staphylococcus aureus, produced by Streptomyces sp. K04-0144 II. Biological activities. J Antibiot 61: 7-10 (2008)

8. Shiring EB, Gottlieb D. Methods for characterization of Streptomyces species. Int J Syst Bacteriol 16: 313-340 (1966)

9. Waksman SA (Ed.). Classification, identification and description of genera and species. In The actinomycetes. Vol. 2. Williams and Wilkins Co. Baltimore (1961)

10. Color Harmony Manual, 4th. ed. Container Corporation of America, Chicago (1958)

11. Pridham TG, Gottlieb D. The utilization of carbon compounds by some Actinomycetales as an aid for species determination. J Bacteriol 56: 107-114 (1948)

12. Becker B, Lechevalier MP, Lechevalier HA. Chemical composition of cell-wall preparation from strains of various form-genera of aerobic actinomycetes. Appl Microbiol 13: 236-243 (1965)

13. Collins MD, Goodfellow M, Minnikin DE. Distribution of menaquinones in actinomycetes and corynebacteria. J Gen Microbiol 100: 221-230 (1977)

14. Tamaoka J, Katayama-Fujiwara Y, Kuraishi H. Analysis of bacterial menaquinone mixtures by high performance liquid chromatography. J Appl Bacteriol 54: 31-36 (1983)

15. Williams ST, Goodfellow M, Alderson G. Genus Streptomyces Waksman and Henrici 1943. In Bergey's Manual of Systematic Bacteriology. Volume 4. Ed., Wiliams
ST et al., pp. 2452-2492, Williams \& Wilkins Co. (1989)

16. Ohta K, Kasahara F, Ishimaru T, Wada Y, Kanamaru T. Structures of fibrostatins, new inhibitors of prolyl hydroxylase. J Antibiot 40: 1239-1248 (1987)

17. Wolfrom ML, Lemieux RU, Olin SM. Configurational correlation of L-(levo)-glyceraldehyde with natural (dextro)alanine by a direct chemical method. J Am Chem Soc 71: 2870-2873 (1949)

18. Birnbaum SM, Levintow L, Kingsley RB, Greenstein JP. Specificity of amino acid acylases. J Biol Chem 194: 455-470 (1952)

19. Okuhara M, Harada T. Formation of $N$-acetyl-L-alanine and $\mathrm{N}$-acetylglycine from glucose by Candida tropicalis $\mathrm{OH} 23$. Biochim Biophys Acta 244: 16-18 (1971)

20. Cristina GM, Siomoes MF, Duarte A, Rodriguez B. Labdane and kauren diterpenoids from Plectranthus fruticosus. J Nat Prod 66: 491-496 (2003)

21. Bohlmann F, Fritz U. Neue diterpene und acetylenverbindungen aus Nidorella-arten. Phytochemistry 17: 1769-1772 (1978)

22. Asakawa Y, Toyota M, Takemoto T. New diterpenes from Porella perrottetiana. Phytochemistry 18: 1681-1685 (1979)

23. Hashimoto T, Shiki K, Tanaka M, Takaoka S, Asakawa Y. Chemical conversion of labdane-type diterpenoid isolated from the liverwort Porella perrottetiana into (-)-Ambrox. Heterocycles 49: 315-325 (1998)

24. Ohta K., Kasahara F., Ishimaru T., Wada Y., Kanamaru T, Okazaki H. Structures of fibrostatins, new inhibitors of prolylhydroxylase. J Antibiot 40: 1239-1248 (1987)

25. Kondo H, Naitou K, Nakajima S, Kojiri K, Suzuki H, Ouchi K, (Banyu Pharm. Co.) Japan Pat. 94-25183 (1994) 